\title{
Case report. Kiemcelneoplasie in situ in een monotestis hoeft niet direct behandeld te worden
}

\author{
Ruud J. G. Mathijssen · Jelle J. G. Nijs · Kathleen W. M. D'Hauwers · Rik de Jongh
}

Geaccepteerd op: 2 november 2021 / Published online: 29 november 2021

(C) The Author(s) 2021

\begin{abstract}
Samenvatting Dit case report beschrijft een 32-jarige man met kiemcelneoplasie in situ (GCNIS) na partiële orchidectomie en contralaterale orchidectomie in verband met een gemengde kiemceltumor. De behandeling van GCNIS kan bestaan uit radiotherapie, orchidectomie of surveillance. Bij het kiezen van de therapie is het belangrijk om rekening te houden met een mogelijke kinderwens, de hormonale status, het risico op het ontwikkelen van (recidief) zaadbalkanker en de voor- en nadelen van iedere behandeling. Deze casus laat zien dat surveillance beleid omwille van een actieve kinderwens op korte termijn veilig kan zijn. Retrospectief is bij verdenking op bilaterale zaadbalkanker overleg met een academisch testisexpertisecentrum en cryosemenpreservatie bij een aanwezige kinderwens te adviseren alvorens te starten met behandeling.
\end{abstract}

Trefwoorden kiemcelneoplasie in situ - monotestis . surveillance

drs. R. J. G. Mathijssen

afdeling Urologie, Canisius-Wilhelmina Ziekenhuis,

Nijmegen, Nederland

J. J. G. Nijs

Máxima Medisch Centrum, Eindhoven, Nederland

dr. K. W. M. D'Hauwers

afdeling Urologie, Radboud Universitair Medisch Centrum,

Nijmegen, Nederland

dr. R. de Jongh $(\bowtie)$

afdeling Urologie, Catharina Ziekenhuis, Eindhoven,

Nederland

rik.d.jongh@catharinaziekenhuis.nl
Testicular germ cell neoplasia in situ in a solitary testis does not necessary to be treated directly. A case report

Abstract This case report describes a 32-year-old man with germ cell neoplasia in situ (GCNIS) after partial orchidectomy and contralateral orchidectomy because of a mixed germ cell tumor. The treatment of GCNIS in a solitary testis consists of radiotherapy, orchidectomy or surveillance. When choosing a treatment, it is important to take into account the desire to have children, the hormonal status, the risk of developing (recurrent) testicular cancer and the advantages and disadvantages of each treatment. This case shows that surveillance in case of an active desire to have children is safe in the short term and can have advantages over radiotherapy. In retrospect, when there is suspicion for bilateral testicular cancer, consultation with an Academic Testis Expertise Centre and cryosemen preservation is recommended when there is a desire to have children.

Keywords germ cell neoplasia in situ · solitary testis · surveillance

\section{Introductie}

Zaadbalkanker is de meest voorkomende maligniteit bij mannen tussen 14 en 44 jaar [1]. Bij 1 tot $2 \%$ van deze mannen komt zaadbalkanker bilateraal voor. 2 De standaardbehandeling voor zaadbalkanker is een inguïnale radicale orchidectomie. Een partiële orchidectomie kan worden overwogen indien de grootte van de tumor $(<2 \mathrm{~cm})$ dit toelaat. Wanneer kiemcelneoplasie in situ (testicular germ cell neoplasia in situ, GCNIS) wordt gevonden, kan de behandeling bestaan uit radiotherapie of orchidectomie; hierbij moet re- 


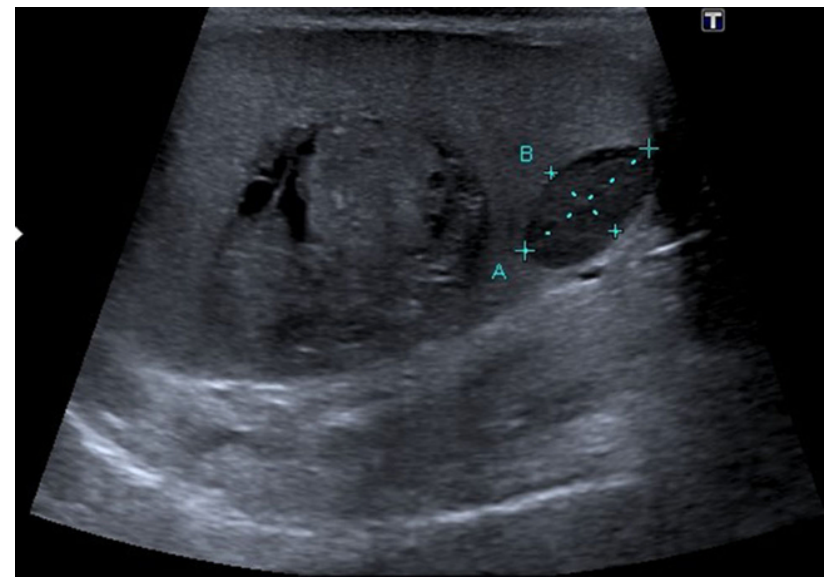

Figuur 1 De rechter testikel met twee laesies: een gemengde cysteus solide laesie van $27 \mathrm{~mm}$ en een tweede echoarme laesie subcapsulair van $14-8 \mathrm{~mm}$

kening gehouden worden met de hormonale status, fertiliteitswensen en curatiemogelijkheden.

\section{Casus}

Een 32-jarige man meldt zich op de polikliniek Urologie met een zwelling in de rechter testis sinds twee dagen. Er is geen relevante voorgeschiedenis en er zijn geen risicofactoren (testisatrofie, cryptorchisme, subfertiliteit, positieve familieanamnese) voor zaadbalkanker aanwezig. Patiënt heeft een partner en samen hebben ze een dochtertje. Er is nog een actieve kinderwens. Bij lichamelijk onderzoek wordt een solide zwelling gevoeld in de rechter testis, de linker testis voelt normaal aan. Echo scrotum laat een bilaterale testistumor zien. In de rechter testis worden een gemengde cysteus solide laesie van $27 \mathrm{~mm}$ en een subcapsulaire echoarme laesie van $14,8 \mathrm{~mm}$ aangetroffen (fig. 1). In de linker testis wordt een laesie nabij de rete testis van $8,4 \mathrm{~mm}$ aangetroffen (fig. 2). Bloedonderzoek laat een verhoogd alfafoetoproteïne ( $\alpha$-FP, 110 uG/l) zien; andere tumormarkers zijn niet verhoogd (LD 210 U/1, HCG (bèta) <0,10 IU/1). Op CT-scans van de thorax en abdomen zijn geen metastasen of lymfadenopathie te zien.

Een inguïnale orchidectomie rechts wordt uitgevoerd zonder plaatsing van een testisprothese, in overleg met patiënt. Pathologisch onderzoek laat een multifocale kiemceltumor zien bestaande uit een seminoom (diameter $1,3 \mathrm{~cm}$ ) en een non-seminoom (diameter $2,3 \mathrm{~cm}$ ) opgebouwd uit matuur teratoom (85\%), een yolk sac tumor (12\%) en een embryonaal carcinoom (3\%). Invasieve groei blijkt beperkt tot de testis, er is geen uitbreiding in de rete testis en er wordt geen (lymf)angio-invasie aangetroffen. Het snijvlak van de funiculus spermaticus is vrij. In het overig testisparenchym wordt GCNIS gevonden. De epididymis laat geen afwijkingen zien. Het postoperatief beloop is ongecompliceerd. De $\alpha$-FP daalde naar een normaal niveau $(2,4 \mathrm{uG} / \mathrm{l})$ binnen twee weken.

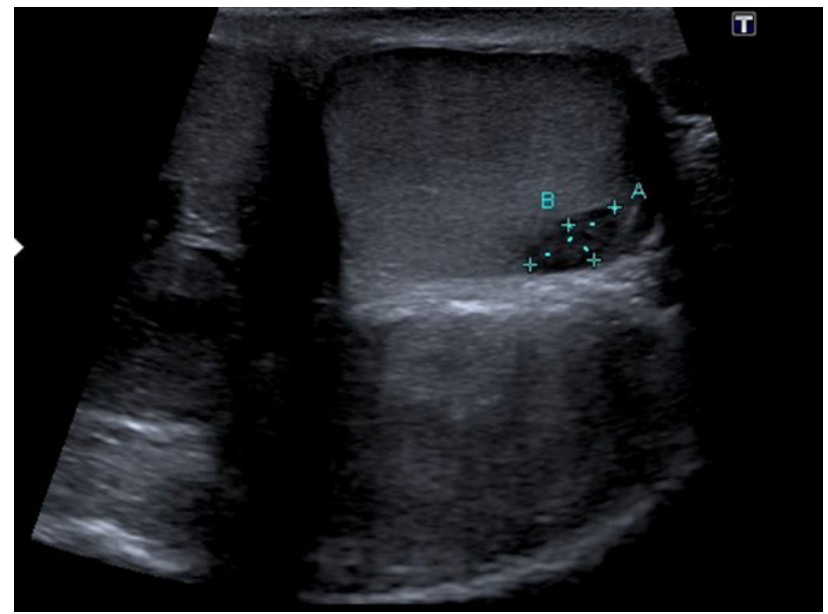

Figuur 2 De linker testikel met een laesie nabij de rete testis van $8-4 \mathrm{~mm}$

De patiënt wordt verwezen naar een academisch centrum voor een partiële orchidectomie links (fig. 3). Preoperatief wordt semen gecryopreserveerd, derhalve is er peroperatief geen TEsticulaire Sperma Extractie (TESE) verricht. Pathologisch onderzoek toont seminoom en GCNIS.

Voor het vervolgbeleid betreffende de GCNIS in de linker monotestis zijn meerdere opties met patiënt besproken: (uitgestelde) radiotherapie, orchidectomie of surveillance. Na voorlichting over de voor- en nadelen van iedere behandeling is gezamenlijk besloten tot surveillance, met het advies om maandelijks zelfonderzoek te verrichten van de monotestis volgens de reminder-app van de Stichting Zaadbalkanker.

De patiënt is conform de 'EAU-richtlijn Non seminoma' de eerste twee jaar om de drie maanden gezien voor poliklinische controles met tumormarkers en aanvullend echografie van de monotestis. Het derde jaar vonden de poliklinische controles om de vier maanden plaats. Een CT-thorax/abdomen is gemaakt na 6, 12, 24 en 36 maanden. Na drie jaar followup is er geen recidief. De tumormarkers zijn normaal

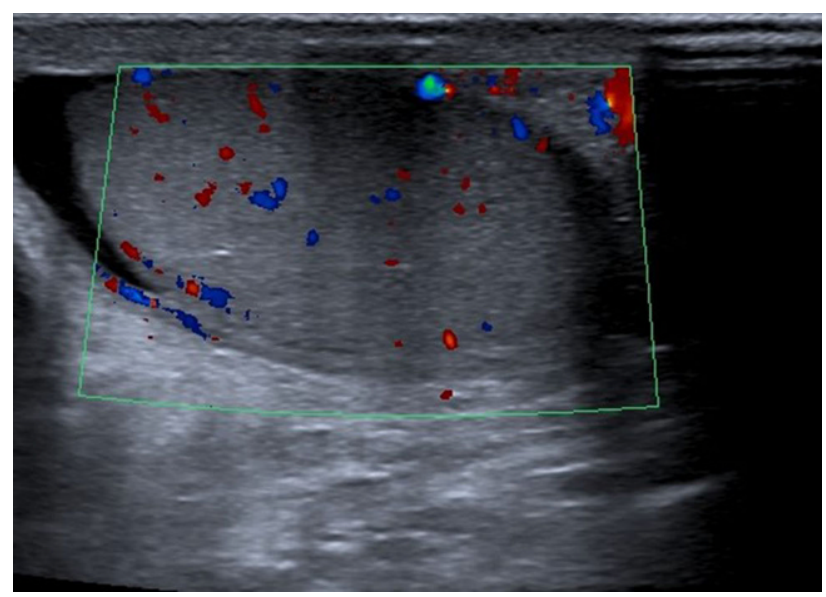

Figuur 3 Status na partiële orchidectomie links met een nagenoeg normaal volume van de linker testis 
en het testosterongehalte bedraagt $14 \mathrm{nmol} / \mathrm{l}$. De patiënt heeft via de natuurlijke weg een tweede kind verwekt. Maandelijks zelfonderzoek is als continue aanbeveling herhaald.

\section{Discussie}

GCNIS (voorheen bekend als carcinoma in situ (CIS), intratubulaire kiemcelneoplasie van ongeclassificeerd type (intratubular germ cell neoplasia, unclassified of IGCNU) en testiculaire intra-epitheliale neoplasie (TIN)) is een pre-invasieve laesie die geassocieerd is met postpuberale maligne kiemceltumoren van de testis [1]. Vrijwel alle testiculaire kiemceltumoren (testicular germ cell tumors, GCT's), met uitzondering van spermatocytisch seminoom bij oudere mannen en dooierzaktumoren en mature teratomen bij kinderen, komen voort uit deze niet-epitheliale laesies [2]. Bij de volwassen GCT's wordt GCNIS bij $88 \%$ in het aangrenzend weefsel aangetroffen en bij $5 \%$ in de contralaterale testis [3]. De prevalentie van GCNIS bij volwassen mannen in de algemene populatie varieert tussen 0,4 en $0,8 \%$ [4].

De vraag is of GCNIS in een monotestis (direct) behandeld moet worden of dat surveillance ook veilig kan zijn. GCNIS lijkt zich in ten minste $50 \%$ van de gevallen te ontwikkelen tot zaadbalkanker binnen vijf jaar [5]. GCNIS komt in 5\% van de contralaterale testis voor bij mannen met zaadbalkanker, terwijl de prevalentie van bilateraal zaadbalkanker $1-2 \%$ bedraagt, wat impliceert dat niet alle GCNIS zich ontwikkelen tot kanker $[2,5]$. In de literatuur wordt ook beschreven dat GCNIS kan uitdoven [5].

Voor de behandeling van unilaterale GCNIS met een gezonde contralaterale testis wordt in de Europese richtlijn een orchidectomie of strikte surveillance geadviseerd, afhankelijk van de voorkeur van de patiënt [6]. De Amerikaanse richtlijn raadt radiotherapie (18-20 Gy in fracties van 2Gy) aan indien de patiënt de voorkeur geeft aan het verkleinen van het risico op zaadbalkanker met behoud van de testikel [7]. Voorlichting aan de patiënt met betrekking tot mogelijke infertiliteit en de noodzaak tot androgeensuppletie wordt in beide richtlijnen benadrukt [6]. De Europese richtlijn maakt, in tegenstelling tot Amerikaanse, onderscheid tussen GCNIS met een gezonde contralaterale testis en GCNIS in een monotestis. In het laatste geval bestaat de behandeling uit radiotherapie (18-20 Gy in fracties van $2 \mathrm{~Gy}$ ) of, in het geval van een patiënt met kinderwens, surveillance [6]. Bij een radiotherapeutische behandeling worden de leydigcellen gedeeltelijk gespaard, waardoor de androgeenproductie bewaard kan blijven [8]. In ongeveer $25 \%$ van de gevallen is echter toch hormoonsuppletie nodig $[9,10]$. Met radiotherapie kan curatie worden bereikt in ongeveer $97,5 \%$ van de gevallen, maar infertiliteit kan zelden worden voorkomen omdat de spermatogoniale stamcel volledig wordt vernietigd [11, 12].
Gezien de kinderwens van patiënt en partner, de geconstateerde normospermie tijdens semenpreservatie en de wens tot behoud van hormoonstatus is gezamenlijk gekozen voor surveillance. Een belangrijk argument hiervoor is de hoge overlevingskans indien GCNIS zich ontwikkelt tot kanker. Zaadbalkanker in stadium 1 heeft een 15-jaarsoverleving van 99\% [13]. Het lijkt dus veilig om initieel niet te kiezen voor radiotherapie bij GCNIS in een monotestis, mits strakke periodieke echografische controles van de monotestis en zelfonderzoek deel uitmaken van de follow-up. Surveillance heeft geen nadelig effect op de androgeenstatus. Wel is het belangrijk om rekening te houden met de impact van surveillance op de psyche van de patiënt. Verder is er geen eenduidigheid met betrekking tot follow-up, schema en duur van surveillance. We hebben er zelf voor gekozen om het followupschema te volgen van de EAU-richtlijn. Verlenging van de follow-upduur met echografische controles van de testis tot zeker 10 jaar lijkt het advies van keuze, gezien de grote kans op het ontwikkelen van zaadbalkanker. Maandelijks zelfonderzoek levenslang blijft aan te bevelen.

Uitgestelde radiotherapie van de monotestis, na een voltooide kinderwens, kan een orchidectomie voorkomen. Het tijdstip van uitgestelde radiotherapie is arbitrair; wellicht is bestraling binnen vijf jaar te adviseren, aangezien ongeveer $50 \%$ van de patiënten in de loop van vijf jaar zaadbalkanker ontwikkelt. Bij (uitgestelde) radiotherapie kan echter ook sprake zijn van overbehandeling, aangezien GCNIS kan uitdoven en deze zich niet bij alle patiënten lijkt te ontwikkelen tot zaadbalkanker. Verder dient rekening te worden gehouden met een verhoogde kans op het ontwikkelen van secundaire maligniteiten bij bestralingstherapie van jonge mensen [14].

Terugkijkend is het te adviseren om bij bilaterale zaadbalkanker te overleggen met een academisch testisexpertisecentrum alvorens te starten met een behandeling. In de meest recente versie van de EAUrichtlijn is het advies om cryosemenpreservatie te verrichten bij aanwezige kinderwens alvorens een orchidectomie uit te voeren [6]. Als de semenanalyse negatief uitvalt, is verwijzing naar een testisexpertisecentrum aan te bevelen waar orchidectomie en TESE gelijktijdig kunnen worden uitgevoerd. Verder is aan te bevelen om de orchidectomie en partiële orchidectomie tijdens dezelfde operatie uit te voeren.

\section{Conclusie}

Bij het maken van een keuze voor het beleid van GCNIS is voorafgaand overleg met een testisexpertisecentrum aan te bevelen en dient rekening gehouden te worden met de belangen van de patiënt. Radiotherapie van de monotestis veroorzaakt infertiliteit en op de lange termijn is in ongeveer $25 \%$ van de gevallen androgeensuppletie noodzakelijk. Surveillancebeleid 
op de korte termijn lijkt veilig bij een patiënt met normospermie en een actieve kinderwens.

Open Access This article is distributed under the terms of the Creative Commons Attribution 4.0 International License (http://creativecommons.org/licenses/by/4.0/), which permits unrestricted use, distribution, and reproduction in any medium, provided you give appropriate credit to the original author(s) and the source, provide a link to the Creative Commons license, and indicate if changes were made.

\section{Literatuur}

1. BerneyDM,Looijenga LH, Idrees M, OosterhuisJW, RajpertDe Meyts E, Ulbright TM, et al. Germ cell neoplasia in situ (GCNIS): evolution of the current nomenclature for testicular pre-invasive germ cell malignancy. Histopathology. 2016;69(1):7-10.

2. Moch H, Cubilla AL, Humphrey PA, Reuter VE, UlbrightTM. The 2016 WHO classification of tumours of the urinary system and male genital organs_-part a: renal, penile, and testicular tumours. Eur Urol. 2016;70(1):93-105.

3. Cheng L, Lyu B, Roth LM. Perspectives on testicular germ cell neoplasms. Hum Pathol. 2017;59:10-25.

4. Sharma P, Dhillon J, Sexton WJ. Intratubular germ cell neoplasia of the testis, bilateral testicular cancer, and aberrant histologies. Urol Clin North Am. 2015;42(3):277-85.

5. Hoei-Hansen CE, Rajpert-de Meyts E, Daugaard G, Skakkebaek NE. Carcinoma in situ testis, the progenitor of testicular germ cell tumours: a clinical review. Ann Oncol. 2005;16(6):863-8.

6. Laguna MP, Albers P, Algaba F, Bokemeyer C, Boormans JL, Fischer S, et al. EAU Guidelines on Testicular Cancer 2020. European Association of Urology Guidelines 2020 Edition presented at the EAU Annual Congress; 2020; Amsterdam. Arnhem: European Association of Urology Guidelines Office; 2020.

7. Stephenson A, Eggener SE, Bass EB, Chelnick DM, Daneshmand S, Feldman D, et al. Diagnosis and treatment of early stage testicular cancer: AUA guideline. J Urol. 2019;202(2):272-81.

8. Bazzi WM, Raheem OA, Stroup SP, Kane CJ, Derweesh IH, Downs TM. Partial orchiectomy and testis intratubular germ cell neoplasia: World literature review. Urol Ann. 2011;3(3):115-8.

9. Petersen PM, Giwercman A, Daugaard G, Rørth M, Petersen JH, Skakkeaek NE, et al. Effect of graded testicular doses of radiotherapy in patients treated for carcinoma-in-situ in the testis. JClin Oncol. 2002;20(6):1537-43.

10. Giwercman A, Maase H von der, Berthelsen JG, Rørth M, Bertelsen A, Skakkebaek NE. Localized irradiation of testes with carcinoma in situ: effects on Leydig cell function and eradication of malignant germ cells in 20 patients. J Clin Endocrinol Metabol. 1991;73(3):596-603.

11. Classen J, Souchon R, Herrmann E, Bamberg M. Stellenwert der Strahlentherapie im interdisziplinären Management testikulärer Keimzelltumoren. Urologe. 2000;39(2):126-32.

12. Dieckmann KP, Classen J, Souchon R, Loy V. Management of testicular intraepithelial neoplasia (TIN) - a review based on the principles of evidence-based medicine. Wien Klin Wochenschr. 2001;113(1-2):7-14.

13. Cheng L, Albers P, Berney DM, Feldman DR, Daugaard G, Gilligan T, et al. Testicular cancer. Nat Rev Dis Prim. 2018;4(1):29.

14. Berrington de Gonzalez A, Curtis RE, Kry SF, Gilbert E, LamartS, et al. Proportion of second cancers attributable to radiotherapy in adults: a cohort study in the USSEER cancer registries. Lancet Oncol. 2011;12(4):353-60.

drs. Ruud J.G. Mathijssen, anios urologie

Jelle J.G. Nijs, coassistent

dr. Kathleen W. M. D’Hauwers, uroloog

dr. Rik de Jongh, uroloog 